\title{
Detection of Subclinical Left Ventricular Dysfunction by Two-Dimensional Speckle Tracking and Tissue Doppler Echocardiography in Young Patients with Type 1 Diabetes Mellitus
}

\author{
Mohamed Elsayed Abdelfattah ${ }^{1 *}$, Reda Biomy ${ }^{1}$, Mohamed Hamouda ${ }^{2}$ and Hany H Ebaid ${ }^{2}$ \\ ${ }^{1}$ Department of Cardiology, Faculty of Medicine, Kafr Elsheikh University, Egypt \\ ${ }^{2}$ Department of Cardiology, Faculty of Medicine, Benha University, Egypt
}

Submission: March 08, 2019; Published: March 26, 2019

*Corresponding author: Mohamed Elsayed Abdelfattah, Department of Cardiology, Faculty of Medicine, Kafr Elsheikh University, Egypt

Abstract

Objective: The study aimed to assess left ventricular systolic and diastolic function in asymptomatic patients with type 1 diabetes mellitus by conventional, 2D speckle tracking and tissue doppler echocardiography to detect subclinical left ventricular dysfunction in this group of patients before developing overt clinical diabetic cardiomyopathy.

Methods: The Study was a case control study that was done on 100 participants who were divided equally into 2 groups, diabetic group and healthy control group. Each group was subjected to full history taking, complete clinical examination, ECG, conventional, tissue doppler and strain echocardiography. HBA1c level was done for diabetic group to detect correlation between diabetic control and GLS\%.

Results: The 2 groups were compared regarding demographic data, anthropometric measures, blood pressure measures, conventional, tissue doppler and strain echocardiography. There was a highly statistically significant difference between the 2 groups regarding A wave velocity, E/A ratio, AP2C LS, AP3C LS, AP4C LS and GLS with P value $<0.001$ and statistically significant difference in deceleration time DT with P value 0.023 . It also revealed that there was a positive significant correlation between duration of diabetes, HBA1c level and GLS\%

Conclusion: GLS appears to be a good tool for early detection of subclinical LV systolic dysfunction. Long duration and poor control of diabetes mellitus are important factors for developing diabetic cardiomyopathy.

Keywords: Type 1 diabetes; Diabetic cardiomyopathy; Tissue Doppler; Global longitudinal strain

Abbrevations: DT: Deceleration Time; GLS: Global longitudinal strain

\section{Introduction}

Type 1 diabetes mellitus is a disorder characterized by autoimmune-mediated destruction of pancreatic $\beta$ cells resulting in absolute insulin deficiency, so it requires exogenous insulin replacement. It affects all cells and almost all organs (especially the eyes, kidneys, heart, and blood vessels) [1].

Cardiovascular diseases are now one of the most common co morbidities and causes of death in diabetic patients [2].

The premature development of coronary atherosclerosis is the most well-known heart disease in diabetes, however, a special subset of heart failure in diabetes has been proposed, the diabetic cardiomyopathy, which is myocardial dysfunction not caused by ischemia, valvular disease or hypertension [3].
The exact cause remains unclear. It is generally accepted that the most important mechanisms are hyperglycemia, increased free fatty acids, activation of the rennin angiotensin system, microangiopathy, increased oxidative stress, and cardiac autonomic neuropathy [4].

All these underlying pathogenic conditions may change cardiac structure and may lead to cardiac fibrosis [5].

The longer duration of diabetes, poor glycemic control and age are important factors contributing towards the development of such complications [6].

These changes are usually progressive and silent atearly stages. Early identification of subclinical systolic or diastolic dysfunction 


\section{Journal of Cardiology \& Cardiovascular Therapy}

is of great importance. Speckle tracking echocardiography (STE) has emerged as an accurate quantitative technique to detect these changes by assessment of global and regional myocardial deformation parameters $[7,8]$.

\section{Methods}

\section{Study population}

The present study is a case control study included 100 participants, were divided into 2 equal groups, diabetic group and healthy control group in the age between 15- 35 years.

Diabetic group included patients with type 1 diabetes mellitus for at least 2 years in the age between 15-35 years.

We excluded diabetic patients who had history of smoking, hypertension, documented coronary artery disease, valvular heart disease, chronic kidney disease, significant arrhythmia as $\mathrm{AF}$ and $\mathrm{LV}$ dysfunction EF less than 50\%.

A thorough history, complete clinical examination, ECG and conventional, tissue doppler and strain echocardiography were done to the 2 groups. HBA1c level were done to the diabetic group.

Global longitudinal strain was used as an indicator of subclinical LV systolic dysfunction. Correlation between HBA1c level, duration of diabetes and all studied parameters (demographic, anthropometric, blood pressure measures, conventional, tissue doppler and strain echocardiographic parameters) to detect relation between duration of diabetes, glycemic control and developing of LV dysfunction.

\section{Statistical analysis}

Data were collected, revised, coded and entered to the Statistical Package for Social Science (IBM SPSS) version 23.

Spearman correlation coefficients were used to assess the correlation between two quantitative parameters in the same group.

The confidence interval was set to $95 \%$ and the margin of error accepted was set to $5 \%$. So, the p-value was considered significant as the following:

P-value $>0.05$ : Non significant (NS), P-value $<0.05$ : Significant (S), P-value < 0.01: Highly significant (HS).

\section{Results}

100 participants were enrolled in this study. $50 \%$ were control and $50 \%$ were diabetic patients, $56 \%$ of them were males and $44 \%$ were females for both groups (P value 1.000). The mean age of control group was slightly more than the diabetic group [24.08 $\pm 3.73]$ years and $[22.50 \pm 4.59]$ years respectively but with no significant difference (P value 0.062).

No statistically significant difference between the 2 groups regarding demographic data, anthropometric and blood pressure measures (P value $>0.05$ ) (Table 1$)$.

Table 1: Demographic, anthropometric measures and clinical data of control and patients.

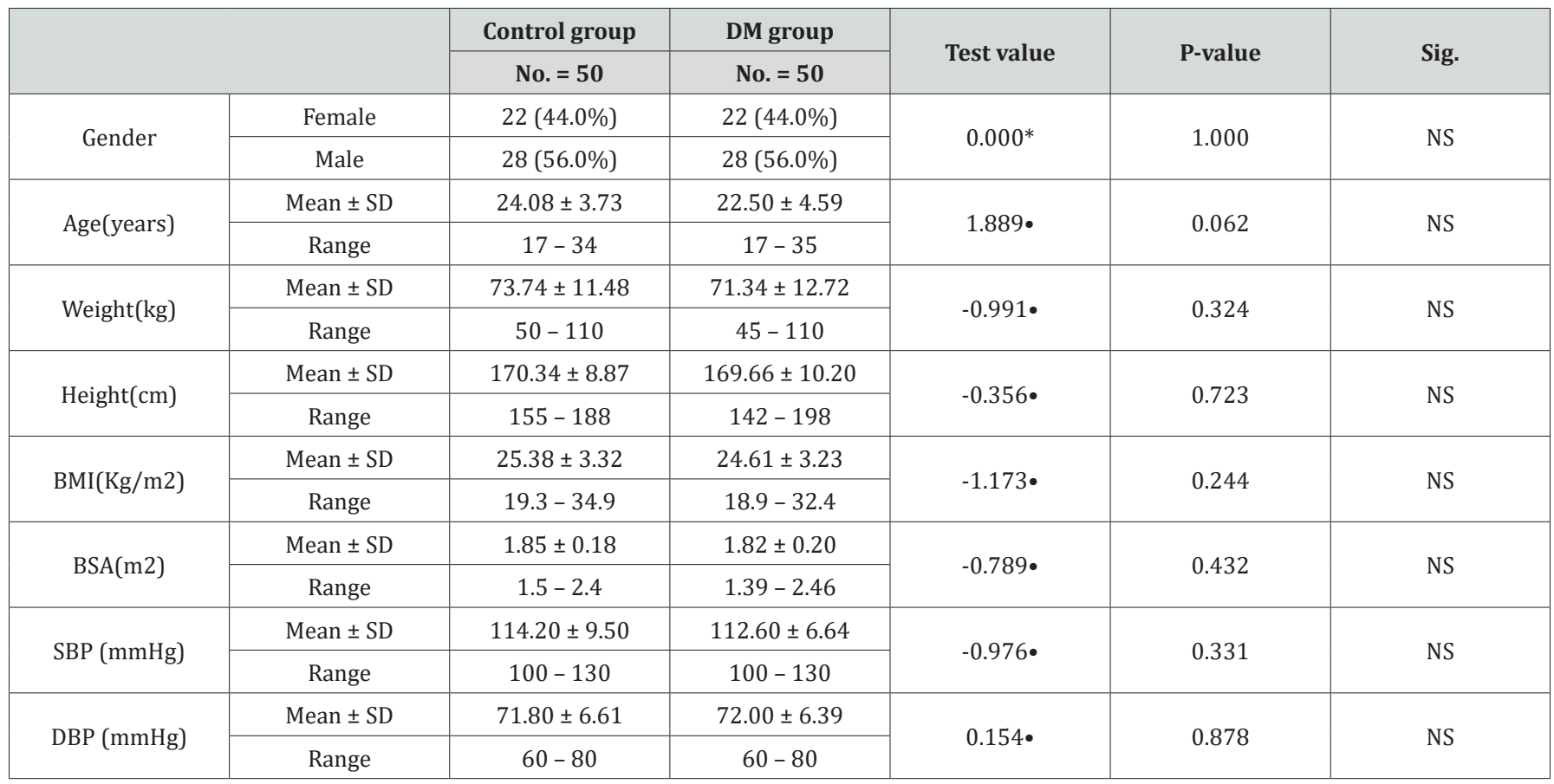

\section{Conventional echocardiography parameters}

The results showed that the 2 groups were comparable regarding conventional echocardiographic data [LVEDD, LVESD,
IVST, PWT, LA, Ao, EF and FS] with no statistically significant difference found between them $(\mathrm{P}>0.05)$ (Table 2). 
Table 2: Conventional echocardiographic parameters.

\begin{tabular}{|c|c|c|c|c|c|c|}
\hline & & Control group & DM group & \multirow{2}{*}{ Test value• } & \multirow{2}{*}{ P-value } & \multirow{2}{*}{ Sig. } \\
\hline & & No. $=\mathbf{5 0}$ & No. $=\mathbf{5 0}$ & & & \\
\hline \multirow{2}{*}{$\operatorname{LVEDD}(\mathrm{cm})$} & Mean \pm SD & $4.60 \pm 0.42$ & $4.54 \pm 0.55$ & \multirow{2}{*}{-0.675} & \multirow{2}{*}{0.501} & \multirow{2}{*}{ NS } \\
\hline & Range & $3.7-5.6$ & $3.3-5.7$ & & & \\
\hline \multirow{2}{*}{$\operatorname{LVESD}(\mathrm{cm})$} & Mean \pm SD & $2.87 \pm 0.31$ & $2.94 \pm 0.40$ & \multirow{2}{*}{1.014} & \multirow{2}{*}{0.313} & \multirow{2}{*}{ NS } \\
\hline & Range & $2.3-3.5$ & $2.1-3.8$ & & & \\
\hline \multirow{2}{*}{ IVST(cm) } & Mean \pm SD & $0.84 \pm 0.10$ & $0.84 \pm 0.11$ & \multirow{2}{*}{0.000} & \multirow{2}{*}{1.000} & \multirow{2}{*}{ NS } \\
\hline & Range & $0.7-1.1$ & $0.6-1.1$ & & & \\
\hline \multirow{2}{*}{$\mathrm{PWT}(\mathrm{cm})$} & Mean \pm SD & $0.82 \pm 0.10$ & $0.81 \pm 0.13$ & \multirow{2}{*}{-0.526} & \multirow{2}{*}{0.600} & \multirow{2}{*}{ NS } \\
\hline & Range & $0.6-1.1$ & $0.6-1.1$ & & & \\
\hline \multirow{2}{*}{$\mathrm{LA}(\mathrm{cm})$} & Mean \pm SD & $3.06 \pm 0.33$ & $3.04 \pm 0.44$ & \multirow{2}{*}{-0.308} & \multirow{2}{*}{0.758} & \multirow{2}{*}{ NS } \\
\hline & Range & $2.4-3.9$ & $2.2-3.9$ & & & \\
\hline \multirow{2}{*}{$\mathrm{Ao}(\mathrm{cm})$} & Mean \pm SD & $2.82 \pm 0.29$ & $2.73 \pm 0.31$ & \multirow{2}{*}{-1.449} & \multirow{2}{*}{0.151} & \multirow{2}{*}{ NS } \\
\hline & Range & $2-3.4$ & $2.1-3.4$ & & & \\
\hline \multirow{2}{*}{$\mathrm{EF}(\%)$} & Mean \pm SD & $65.32 \pm 4.27$ & $64.20 \pm 4.44$ & \multirow{2}{*}{1.286} & \multirow{2}{*}{0.202} & \multirow{2}{*}{ NS } \\
\hline & Range & $61-77$ & $57-76$ & & & \\
\hline \multirow{2}{*}{ FS (\%) } & Mean \pm SD & $36.10 \pm 3.41$ & $34.86 \pm 3.42$ & \multirow{2}{*}{1.816} & \multirow{2}{*}{0.072} & \multirow{2}{*}{ NS } \\
\hline & Range & $32-46$ & $30-44$ & & & \\
\hline
\end{tabular}

Tissue Doppler, diastolic function and strain parameters

The diabetic group had higher A wave velocity compared to control group with mean A wave velocity was [52.69 \pm 11.21$]$ $\mathrm{cm} / \mathrm{s}$ for the control group and $[72.96 \pm 17.54] \mathrm{cm} / \mathrm{s}$ for the diabetic group, (P value $<0.001$ ), longer deceleration time with mean DT was [198.36 \pm 33.46$] \mathrm{ms}$ for the control group and [217.46 \pm 48.21$] \mathrm{ms}$ for the diabetic group, (P value 0.023), lower $\mathrm{E} / \mathrm{A}$ ratio with mean $\mathrm{E} / \mathrm{A}$ ratio was $[1.85 \pm 0.33]$ for the control group and [1.34 \pm 0.32 ] for the diabetic group, ( $\mathrm{P}$ value $<0.001$ ), also lower longitudinal strain parameters with mean AP2C LS was $[-21.15 \pm 1.95] \%$ for the control group and $[-19.27 \pm 2.21] \%$ for the diabetic group, (P value $<0.001$ ), mean AP3C LS was $[-20.23 \pm$ $1.81] \%$ for the control group and $[-18.45 \pm 2.30] \%$ for the diabetic group, (P value < 0.001), mean AP4C LS was [-21.34 \pm 2.01$] \%$ for the control group and $[-19.13 \pm 2.25] \%$ for the diabetic group, (P value $<0.001)$ and mean GLS was $[-20.91 \pm 1.20] \%$ for the control group and $[-18.95 \pm 2.02] \%$ for the diabetic group, (P value < 0.001).

The 2 groups were comparable regarding Septal S, Lateral S, septal e', lateral e', E wave velocity, average E/e', TR velocity and LAVI.

The results showed that there was a highly statistically significant difference between the 2 studied groups $(\mathrm{P}<0.001)$ as regard AP4C LS, AP2C LS , AP3C LS, GLS, A wave velocity and E/A, while statistically significant difference $(P<0.05)$ as regard deceleration time (DT), and no statistically significant correlation found with the other studied parameters $(\mathrm{P}>0.05)$ (Table 3) \& (Figure 1).

Table 3: Doppler, diastolic function and strain parameters.

\begin{tabular}{|c|c|c|c|c|c|}
\hline & & Control group & DM group & \multirow{2}{*}{ Test value• } & \multirow{2}{*}{ P-value } \\
\hline & & No. $=\mathbf{5 0}$ & No. $=50$ & & \\
\hline \multirow{2}{*}{ Sep S (cm/s) } & Mean \pm SD & $8.83 \pm 0.82$ & $8.71 \pm 0.95$ & \multirow{2}{*}{-0.701} & \multirow{2}{*}{0.485} \\
\hline & Range & $7.1-10.7$ & $6.2-10.7$ & & \\
\hline \multirow{2}{*}{ Lat S (cm/s) } & Mean \pm SD & $10.66 \pm 1.46$ & $10.91 \pm 1.67$ & \multirow{2}{*}{0.782} & \multirow{2}{*}{0.436} \\
\hline & Range & $8.1-14.5$ & $6.8-14.8$ & & \\
\hline \multirow{2}{*}{ AP4C LS (\%) } & Mean \pm SD & $-21.34 \pm 2.01$ & $-19.13 \pm 2.25$ & \multirow{2}{*}{5.175} & \multirow{2}{*}{0.000} \\
\hline & Range & $-26.1--18.4$ & $-22.8--12.5$ & & \\
\hline \multirow{2}{*}{ AP2C LS (\%) } & Mean \pm SD & $-21.15 \pm 1.95$ & $-19.27 \pm 2.21$ & \multirow{2}{*}{4.511} & \multirow{2}{*}{0.000} \\
\hline & Range & $-28.6--17.6$ & $-22.7--12.6$ & & \\
\hline \multirow{2}{*}{ AP3C LS (\%) } & Mean \pm SD & $-20.23 \pm 1.81$ & $-18.45 \pm 2.30$ & \multirow{2}{*}{4.288} & \multirow{2}{*}{0.000} \\
\hline & Range & $-27.2--17.3$ & $-21.9--11.5$ & & \\
\hline
\end{tabular}


Journal of Cardiology \& Cardiovascular Therapy

\begin{tabular}{|c|c|c|c|c|c|}
\hline \multirow{2}{*}{ GLS (\%) } & Mean \pm SD & $-20.91 \pm 1.20$ & $-18.95 \pm 2.02$ & \multirow{2}{*}{5.911} & \multirow{2}{*}{0.000} \\
\hline & Range & $-24.1--19.3$ & $-21.8--12.2$ & & \\
\hline \multirow{2}{*}{ E velocity $(\mathrm{cm} / \mathrm{s})$} & Mean \pm SD & $95.19 \pm 14.31$ & $93.80 \pm 15.85$ & \multirow{2}{*}{-0.462} & \multirow{2}{*}{0.645} \\
\hline & Range & $69-124$ & $67-132$ & & \\
\hline \multirow{2}{*}{ A velocity $(\mathrm{cm} / \mathrm{s})$} & Mean \pm SD & $52.69 \pm 11.21$ & $72.96 \pm 17.54$ & \multirow{2}{*}{6.885} & \multirow{2}{*}{0.000} \\
\hline & Range & $34-90$ & $39-116$ & & \\
\hline \multirow{2}{*}{ Sep e` $(\mathrm{cm} / \mathrm{s})$} & Mean \pm SD & $13.66 \pm 2.27$ & $12.92 \pm 2.07$ & \multirow{2}{*}{-1.716} & \multirow{2}{*}{0.089} \\
\hline & Range & $9-18.9$ & $8.8-17.1$ & & \\
\hline \multirow{2}{*}{ lat $e^{\prime}(\mathrm{cm} / \mathrm{s})$} & Mean \pm SD & $18.47 \pm 2.83$ & $17.83 \pm 2.69$ & \multirow{2}{*}{-1.160} & \multirow{2}{*}{0.249} \\
\hline & Range & $12.5-25.7$ & $12.6-24.9$ & & \\
\hline \multirow{2}{*}{ E/A ratio } & Mean \pm SD & $1.85 \pm 0.33$ & $1.34 \pm 0.32$ & \multirow{2}{*}{-7.842} & \multirow{2}{*}{0.000} \\
\hline & Range & $1.2-2.8$ & $0.8-2.2$ & & \\
\hline \multirow{2}{*}{ Average E/e` } & Mean \pm SD & $6.15 \pm 1.21$ & $6.42 \pm 1.10$ & \multirow{2}{*}{1.179} & \multirow{2}{*}{0.241} \\
\hline & Range & $3.7-9$ & $4.7-8.5$ & & \\
\hline \multirow{2}{*}{ TR velocity $(\mathrm{m} / \mathrm{s})$} & Mean \pm SD & $2.14 \pm 0.25$ & $2.12 \pm 0.26$ & \multirow{2}{*}{-0.311} & \multirow{2}{*}{0.757} \\
\hline & Range & $1.6-2.9$ & $1.6-2.6$ & & \\
\hline \multirow{2}{*}{$\mathrm{DT}(\mathrm{ms})$} & Mean \pm SD & $198.36 \pm 33.46$ & $217.46 \pm 48.21$ & \multirow{2}{*}{2.301} & \multirow{2}{*}{0.023} \\
\hline & Range & $134-292$ & $120-345$ & & \\
\hline \multirow{2}{*}{ LAVI(ml/m2) } & Mean \pm SD & $21.62 \pm 3.46$ & $20.94 \pm 2.24$ & \multirow{2}{*}{-1.165} & \multirow{2}{*}{0.247} \\
\hline & Range & $16-31$ & $14-27$ & & \\
\hline
\end{tabular}



Figure 1: Comparison between study groups regarding longitudinal strain parameters.

\section{Correlation analysis}

The correlation between duration of diabetes and HbA1c level with the other studied parameters in diabetic group was as follow:

There was statistically significant positive correlation found between duration of diabetes and the age of the studied cases (P value < 0.0001), AP4C LS (P value 0.015), AP2C LS (P value 0.005),
AP3C LS (P value 0.004) and GLS (P value 0.003) but no statistically significant correlation found between duration of diabetes with the other studied parameters [weight, height, BMI, BSA, SBP, DBP, LVEDD, LVESD, IVST, PWT, LA, Ao, EF, FS, Sep S velocity, Lat S velocity, E velocity, A velocity, Sepal e` velocity, lateral e` velocity, E/A ratio, Average E/e`, TR velocity, Deceleration time (DT), Left atrial volume index (LAVI)] (P value $>0.05$ ) (Table 4) \& (Figure 2). 


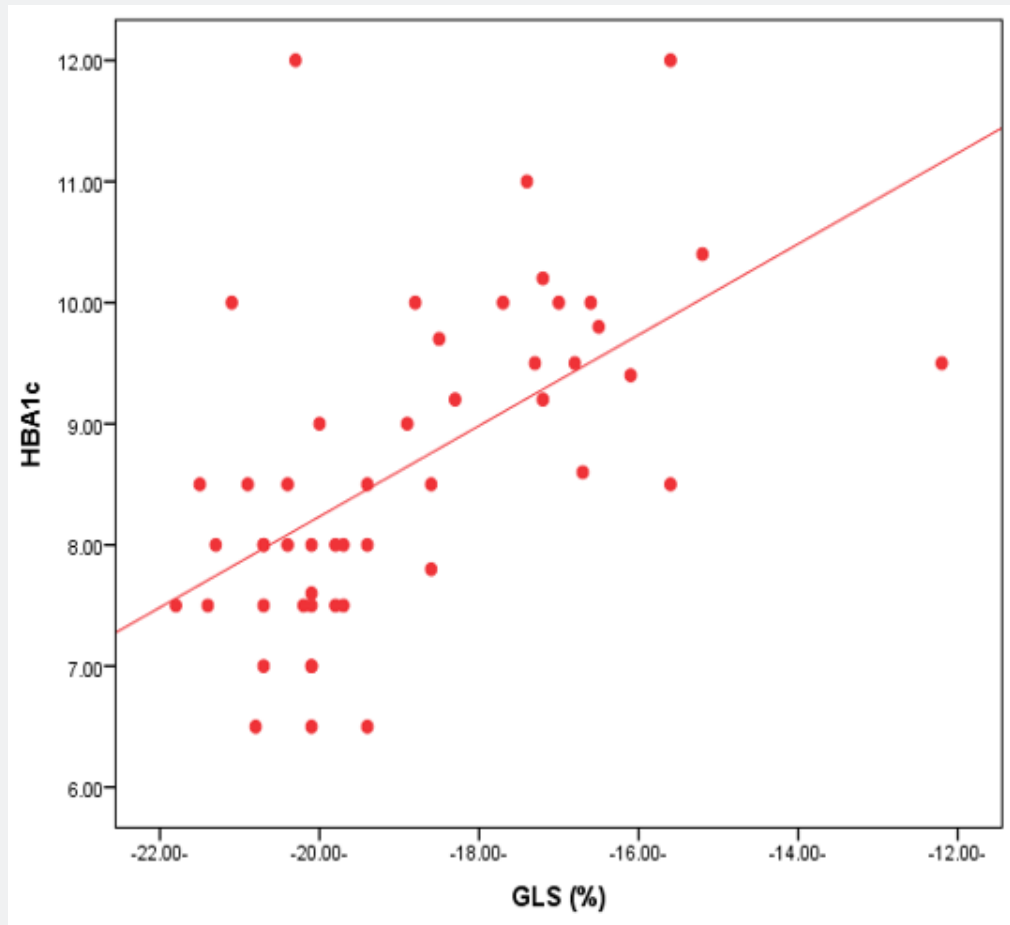

Figure 2: Shows correlation between duration of diabetes and GLS.

There was statistically significant positive correlation found between HBA1c level and BMI (P value 0.023), AP4C LS (P value < 0.001), AP2C LS (P value < 0.001), AP3C LS (P value < 0.001) and GLS (P value $<0.001$ ) but no statistically significant correlation found between HBA1c level with the other studied parameters [the age of the studied cases, weight, height, BSA, SBP, DBP, LVEDD, LVESD, IVST, PWT, LA, Ao, EF, FS, Sep S velocity, Lat S velocity, E velocity, A velocity, Sepal e`velocity, lateral e`velocity, E/A ratio, Average E/e`, TR velocity, Deceleration time (DT), Left atrial volume index (LAVI)] (P value > 0.05) (Table 4) \& (Figure 3).



Figure 3: Shows correlation between HBA1c and GLS. 
Table 4: Correlation between duration of diabetes mellitus and HBA1c level with other study parameters.

\begin{tabular}{|c|c|c|c|c|}
\hline & \multicolumn{2}{|c|}{ Duration of DM (years) } & \multicolumn{2}{|c|}{ HBA1c } \\
\hline & $\mathbf{r}$ & P-value & $\mathbf{R}$ & P-value \\
\hline Age(years) & 0.48 & 0 & 0.123 & 0.397 \\
\hline Weight(kg) & 0.078 & 0.592 & 0.243 & 0.09 \\
\hline Height $(\mathrm{cm})$ & -0.182 & 0.206 & 0.08 & 0.583 \\
\hline $\mathrm{BMI}(\mathrm{Kg} / \mathrm{m} 2)$ & 0.227 & 0.112 & 0.321 & 0.023 \\
\hline $\mathrm{BSA}(\mathrm{m} 2)$ & 0.039 & 0.786 & 0.183 & 0.203 \\
\hline $\mathrm{SBP}(\mathrm{mmHg})$ & -0.075 & 0.606 & -0.091 & 0.529 \\
\hline $\mathrm{DBP}(\mathrm{mmHg})$ & -0.059 & 0.683 & 0.014 & 0.925 \\
\hline $\operatorname{LVEDD}(\mathrm{cm})$ & -0.245 & 0.087 & -0.118 & 0.416 \\
\hline $\operatorname{LVESD}(\mathrm{cm})$ & -0.213 & 0.137 & -0.031 & 0.829 \\
\hline $\operatorname{IVST}(\mathrm{cm})$ & 0.146 & 0.31 & 0.097 & 0.503 \\
\hline $\operatorname{PWT}(\mathrm{cm})$ & 0.189 & 0.19 & 0.125 & 0.387 \\
\hline $\mathrm{LA}(\mathrm{cm})$ & -0.014 & 0.923 & 0.072 & 0.62 \\
\hline $\mathrm{Ao}(\mathrm{cm})$ & -0.121 & 0.401 & -0.095 & 0.511 \\
\hline $\mathrm{EF}(\%)$ & 0 & 0.999 & -0.23 & 0.108 \\
\hline $\mathrm{FS}(\%)$ & 0.014 & 0.926 & -0.242 & 0.09 \\
\hline Sep S(cm/s) & -0.111 & 0.441 & -0.064 & 0.661 \\
\hline Lat $S(\mathrm{~cm} / \mathrm{s})$ & -0.184 & 0.2 & -0.157 & 0.276 \\
\hline AP4C LS(\%) & 0.341 & 0.015 & 0.62 & 0 \\
\hline AP2C LS(\%) & 0.389 & 0.005 & 0.552 & 0 \\
\hline AP3C LS(\%) & 0.403 & 0.004 & 0.513 & 0 \\
\hline GLS (\%) & 0.417 & 0.003 & 0.595 & 0 \\
\hline E velocity $(\mathrm{cm} / \mathrm{s})$ & -0.105 & 0.467 & -0.019 & 0.895 \\
\hline A velocity $(\mathrm{cm} / \mathrm{s})$ & 0.011 & 0.939 & 0.183 & 0.204 \\
\hline Sep e` $(\mathrm{cm} / \mathrm{s})$ & -0.26 & 0.068 & -0.064 & 0.659 \\
\hline lat $\mathrm{e}^{\prime}(\mathrm{cm} / \mathrm{s})$ & -0.092 & 0.527 & -0.078 & 0.592 \\
\hline $\mathrm{E} / \mathrm{A}$ & -0.095 & 0.511 & -0.139 & 0.334 \\
\hline AverageE/e` & 0.141 & 0.329 & 0.095 & 0.51 \\
\hline TR velocity(m/s) & -0.066 & 0.65 & -0.068 & 0.64 \\
\hline DT(ms) & -0.216 & 0.133 & -0.107 & 0.458 \\
\hline $\mathrm{LAVI}(\mathrm{ml} / \mathrm{m} 2)$ & -0.082 & 0.571 & -0.136 & 0.345 \\
\hline
\end{tabular}




\section{Discussion}

In current study, the 2 groups were comparable regarding conventional echocardiographic parameters with no statistically significant difference between them ( $\mathrm{P}$ value $>0.05$ ).

These results were in agreement with those obtained by Tamer et al. [9] and Sameh et al. [10].

We demonstrated that there was statistically significant difference between the 2 studied groups as regard AP4C LS, AP2C LS, AP3C LS, GLS (P value >0.001) (Table 3).

These results are in agreement with results obtained by Altun et al. [11] regarding longitudinal strain parameters which showed that:

AP2C LS (\%) (P value = 0.001), AP3C LS (\%) $(\mathrm{P}$ value $>0.001)$, AP4C LS (\%) (P value > 0.001), G LS (\%) (P value > 0.001).

It was also in agreement with results of GLS obtained by Sameh et al. [10]. (P value $>0.001)$.

It was also in agreement with results of GLS obtained by Tamer et al. [9]. (P value $>0.001$ ).

In our study, the diabetic group had higher values of A wave velocity than control group with statistically significant difference between the 2 groups (P value < 0.01) (Table 3).

These results are in agreement with results obtained by Altun et al. $[11](P$ value $=0.020)$.

It is also in agreement with results obtained by Sameh et al. $[10]$. $(\mathrm{P}$ value $=0.003)$.

In our study, diabetic group had lower values of E/A ratio than control group with statistically significant difference between the 2 groups (P value < 0.01) (Table 3 ).

These results are in agreement with results obtained by Altun et al. [11]. (P value= 0.029).

It is also in agreement with results obtained by Tamer et al. [9]. (P value> 0.01).

Our results are not in agreement with results of E/A ratio obtained by Sameh et al. [10] which showed that there was no statistically significant difference between the 2 groups ( $P$ value $=0.64)$.

In our study, there was a statistically significant positive correlation between duration of diabetes and the age of the studied cases, AP4C LS, AP2C LS, AP3C LS and GLS while no statistically significant correlation found with the other studied parameters (Table 4).

It also showed that there was a statistically significant positive correlation between HBA1c level and BMI, AP4C LS, AP2C LS, AP3C LS and GLS while no statistically significant correlation found with the other studied parameters (Table 4).
Our results are in agreement with results obtained from [911] studies regarding correlation between HBA1c level, duration of diabetes and longitudinal strain parameters.

They showed that poor glycemic control (as indicated by elevation of HBA1c level) and longer duration of diabetes had statistically significant correlation with longitudinal strain parameters. According to data obtained from our study, diabetic group had lower values of GLS which was used as the main indicator for detection of subclinical systolic dysfunction GLS (\%) $-18.95 \pm 2.02$.

ECAVI NORRE study by Sugimoto T et al. [12] A big study that was published in European Heart Journal for reference ranges of normal left ventricular 2D strain and according to it, average GLS for our study age group is:

Males $-22 \pm 2.7$

\section{Females $-23.3 \pm 2.7$}

So according to these study, some diabetic patients who had GLS less than those values may have subclinical left ventricular systolic dysfunction and at risk for progression to overt diabetic cardiomyopathy.

According also to our study data, there is statistically significant difference between the two groups regarding A wave velocity and $\mathrm{E} / \mathrm{A}$ ratio but the other diastolic function parameters were comparable between the 2 groups (septal e', lateral e', average E/e', LAVI, TR velocity), so the two groups had normal diastolic function according to ASE diastolic function guidelines [13].

Global longitudinal strain (GLS) is a good and early indicator for detection of subclinical left ventricular systolic dysfunction which may be affected even before affection of diastolic function.

Longer duration and poor glycemic control of diabetes (HBA1c is an indicator for diabetes control) significantly affect GLS.

\section{Study Limitations}

Some limitations were noted in our study include the limited number of patients in the study; strict exclusion criteria may explain this.

All the patients in our study were from the same geographical area to facilitate performing the studies and collection of data.

The patients diagnosed with subclinical LV dysfunction did not undergo additional imaging or invasive tests as myocardial perfusion imaging or coronary angiography to exclude ischemic causes of this subclinical dysfunction, we speculated that the studied group were young age with no other risk factors with low probability for ischemic heart disease.

\section{Conclusion}

Based on the results of the current study, it can be concluded that diabetes mellitus is an independent causative factor for 
development of systolic dysfunction which can be latent in majority of cases and eventually proceed to overt heart failure (diabetic cardiomyopathy).

Diabetic group had GLS \% lower than control group and this was statistically significant denoting early systolic dysfunction.

There was a statistically significant positive correlation between (duration of diabetes and HBA1C) and AP4C LS, AP2C LS, AP3C LS and GLS.

GLS is a non-invasive good tool for early detection of subclinical left ventricular systolic dysfunction in asymptomatic diabetic patients.

\section{Conflict of Interest}

We declare having no financial or personal relationship with other people or organization that could inappropriately influence our work.

\section{Acknowledgement}

I would like to thank my dear professors who helped me to complete this work.

\section{References}

1. Haller MJ, Silverstein JH, Rosenbloom AL, et al. (2007) Type 1 Diabetes in the child and adolescent. In: Lifshitz F, ed. Pediatrik Endocrinology. New York, NY: Informa healthcare 63-77. 5th edn. Chapter 4.

2. Laing SP, Swerdlow AJ, Slater SD, Burden AC, Morris A, et al. (2003) Mortality from heart disease in a cohort of 23,000 patients with insulin treated diabetes. Diabetologia 46(6): 760-765.

3. Fang ZY, Prins JB, Marwick TH (2004) Diabetic cardiomyopathy: evidence, mechanisms, and therapeutic implications. Endocr Rev 25(4): 543-567.



This work is licensed under Creative Commons Attribution 4.0 License DOI: 10.19080/JOCCT.2019.13.555866
4. Voulgari, Papadogiannis D, Tentolouris N (2010) Diabetic cardiomyopathy: from the pathophysiology of the cardiac myocytes to current diagnosis and management strategies. Vasc Health Risk Manag 6: 883-903.

5. Miki T, Yuda S, Kouzu H, Miura T (2013) Diabetic cardiomyopathy: pathophysiology and clinical features. Heart Fail Rev 18(2): 149-166.

6. Brink SJ (2001) Complications of pediatric and adolescent type 1 diabetes mellitus. Curr Diab Rep 1(1): 47-55.

7. Mondillo S, Galderisi M, Mele D, Cameli M, Lomoriello VS, et al. (2011) Speckle tracking echocardiography. A new technique for assessing myocardial function. J Ultrasound Med 30(1): 71-83.

8. Fontana A, Zambon A, Cesana F, Giannattasio C, Trocino G (2012) Tissue Doppler, triplane echocardiography, and speckle tracking echocardiography: different ways of measuring longitudinal myocardial velocity and deformation parameters. A comparative clinical study. Echocardiography 29(4): 428-437.

9. Tamer Yoldas, Utku Arman, Elif Sagsak, et al. (2017) Subclinical left ventricular systolic and diastolic dysfunction in type 1diabetic children and adolescents with good metabolic control. Echocardiography 10: 1037.

10. Sameh WGB, Heba AH, Ibrahim NE, Mary NR (2016) Assessment of left ventricular function in young type 1 diabetes mellitus patients by twodimensional speckle tracking echocardiography: Relation to duration and control of diabetes. The Egyptian Heart Journal 68(4): 217-225.

11. Altun G, Babaoğlu K, Binnetoğlu K, Özsu E, Yeşiltepe Mutlu RG, et al. (2016) Subclinical left ventricular longitudinal and radial systolic dysfunction in children and adolescents with type 1 diabetes mellitus. Echocardiography 33(7): 1032-1039.

12. Sugimoto T, Dulgheru R, Bernard A, Ilardi F, Contu L, et al. (2017) Echocardiographic reference ranges for normal left ventricular 2D strain: results from the EACVI NORRE study. Eur Heart J Cardiovasc Imaging 18(8): 833-840.

13. Nagueh SF, Appleton CP, Gillebert TC, Marino PN, Oh JK, et al. (2009) Recommendations for the evaluation of left ventricular diastolic function by echocardiography. J Am Soc Echocardiogr 22(2): 107-133.

\begin{tabular}{l} 
Your next submission with Juniper Publishers \\
will reach you the below assets \\
- Quality Editorial service \\
- Swift Peer Review \\
- Reprints availability \\
- E-prints Service \\
- Manuscript Podcast for convenient understanding \\
- Global attainment for your research \\
- Manuscript accessibility in different formats \\
( Pdf, E-pub, Full Text, Audio) \\
- Unceasing customer service \\
Track the below URL for one-step submission \\
https://juniperpublishers.com/online-submission.php \\
\hline
\end{tabular}

